\title{
Validation of SCAR Marker Linked to Genic Male Sterility in Marigold: As a Forward Step towards Marker Assisted Breeding Programme
}

\author{
K.M. Asha ${ }^{1 *}$, Anuradha Sane ${ }^{1}$, Tejaswini ${ }^{1}$, D.C. Lakshaman Reddy ${ }^{1}$, Sateesha R. Patil ${ }^{2}$, \\ Sarvamangala S. Cholin ${ }^{3}$, Mahantesha B.N. Naika ${ }^{2}$ and Raghavendra Gunnaiah ${ }^{3}$ \\ ${ }^{1}$ IIHR Hessaraghatta; Division of ornamental crops, IIHR, Hessaraghatta, \\ Bengaluru- 560089, India \\ ${ }^{2}$ College of Horticulture, Arabhavi, India \\ ${ }^{3}$ College of Horticulture, Bagalkot, India
}

*Corresponding author

\section{A B S T R A C T}

Keywords

Marigold, Genic

Male sterility,

SCAR marker,

Linked marker,

MAS, Validation,

Apetalloid sterile

lines

Article Info

Accepted:

22 January 2019

Available Online:

10 February 2019
The identification of marker tightly linked to male sterility will greatly facilitate for marker assisted selection (MAS) breeding through accurate selection of parental lines in hybrid production. In the present study, to assess the efficiency of previously reported SCAR 4 marker for marker assisted selection was validated by screening the marker in a total of $226 \mathrm{~F}_{2}$ mapping population derived from a cross between male sterile (IIHR10521AB) and a male fertile pure line (IIHRMY7) maintained at IIHR along with bulk segregant analysis. The results showed that the marker segregated in the $F_{2}$ population showing that it is linked to sterility locus. The marker was also validated by screening 12 different apetalloid male sterile lines maintained at IIHR, the results of amplification gave clear and similar band size amplicons present in parents in all the apetalloid sterile lines confirming that it is linked to male sterility and hence this study is significantly useful and can offer a powerful tool for the efficient selection in MAS breeding programmes in marigold.

\section{Introduction}

Marigold (Tagetes erecta L.) is an ornamental plant belonging to the Compositae family. It is grown in many parts of India as well as throughout the World. Marigold is widely grown as a border plant in gardens. Different varieties and flowers are available in various shades of yellow, red, orange, dark orange, and orange brown. The two common species of marigold, both annuals, are distinguished as African marigold ( $T$. erecta) and French marigold (T. patula) and are native to Mexico and Gautemala and were popularly grown as a cut flower, loose flower, pot plant and as a bedding plant in garden and for its medicinal values (Sowbhagya et al., 2004). Prospects of commercialization of marigold are increasing because of its hardy nature with ease to grow, low nutrient requirement and easy availability 
of planting material. Many Tagetes species are known to yield aromatic essential oils which are known as Tagetes oils potential of being used as antimicrobicide (Padalia et al., 2014) and also a rich souce of lutein a natural pigment (Deineka et al., 2008) that can give a good orange shade to foods. The status of marigold, as a source of natural colourant has been reviewed by Verghese $(1996,1998)$ and Sowbhagya et al., (2004). Being rich source of lutein and other carotenoids, marigold flowers make an excellent source of valuable nutraceuticals and safe natural orange colorant in food applications (Sowbhagya et al., 2004). In plant breeding, male sterility has been applied as an effective and economical means of pollination control and it place an important role in plant adaptation and evolution (Darvin 1877). Marigold has a terminal capitulum composed of hundreds of florets with two different types: ray (sterile) florets in the periphery, and disk (fertile) florets in the centre. The male sterility was confirmed to be a recessive genic trait and was reported that spontaneous homeotic conversion of floral organs was the underlying cause of the male sterility in marigold by $\mathrm{He}$ et al., (2010).

Hybrid varieties of $T$. erecta or $T$. erecta $\mathrm{X} T$. patula are being cultivated globally, but $\mathrm{F}_{1}$ hybrid seeds are expensive and their supply is restricted from a few renowned companies only. Marigold male sterile lines are used for cross-breeding purposes (Zhang et al., 2005) and serve to make the hybridization process relatively efficient and economic. Recently it has been reported in marigold that crossing between male sterile lines and inbred lines given hybrid combinations with higher ornamental values, with obvious heterosis over the male parent for most of the ornamental traits (Ai et al., 2015). Fortunately, the existence of male sterility system in marigold has made it easy for the crossing programs in the production of $\mathrm{F}_{1}$ hybrids. However, the GMS system has the limitation that it is difficult to obtain a $100 \%$ male sterile population, making it necessary to manually remove the $50 \%$ fertile plants in order to prevent contamination of the $F_{1}$ hybrid progeny which is time and labor consuming and also difficult to remove prior flowering. This must be achieved prior to flowering and consumes significant time, labor and money (He et al., 2009). However, molecular markers may be used to facilitate the detection of important traits, thereby permitting breeding programmes for elite cultivars to be concluded in a shorter time and in a more cost effective manner (Tanksley et al., 1989). Thus, the identification of molecular markers that are tightly linked to the male sterility locus would permit the early and efficient identification of individual plant genotypes within the breeding populations. There is a very recent report of AFLP and SCAR-based linkage map by He et al., (2010) where they have reported that SCAR 4 marker has been linked to male sterility in marigold which is placed at a distance of $0.3 \mathrm{cM}$ distance from the sterility locus on the linkage map showing that it is tightly linked to sterility gene.

Hence in the present study, to assess the efficiency and practical applicability of SCAR 4 linked marker for Marker Assisted Selection breeding programme it was attempted to validate linked marker in different genetic background of $F_{2}$ population and in 12 different apetalloid male sterile lines which confirmed its linkage with sterility gene.

\section{Materials and Methods}

\section{Primer}

The previously identified SCAR 4 marker which was reported to be linked to male sterility by $\mathrm{He}$ et al., (2009) was validated in the present study. The sequences of SCAR4 marker used in the present study are as follows: 
F1: TGAGTCCAAACCGGACCCGG; R1: ACTGCGTACGAATTAGCACACATTA;

\section{Plant material}

An $F_{2}$ segregating population of 226 progeny plants were generated following the crossing programme involving a cross between contrasting parent's male sterile line (IIHR10521AB) and a pure line (IIHRMY7). Finally, a total of $226 \mathrm{~F}_{2}$ plants segregating for sterility character were obtained which were found to be morphologically indistinguishable prior to flowering. After flowering, the phenotyping of $\mathrm{F}_{2}$ progeny was done based on floral traits. The flowers of the male fertile plants had normal petals in the ray and disc florets whereas, the petals of the ray and disc florets of the male sterile plants degenerated or developed as white filament-like petals and the stamen became yellow filament without pollen inside (Plate 1).

The other different genetic background such as 12 different Apetalloid male sterile lines (Table 1) was also used in the present study to validate the linked marker.

\section{DNA extraction}

The samples for DNA extraction were collected separately from young leaves from both the parents used in crossing programme and from each plant of the $226 \mathrm{~F}_{2}$ plants at young seedling stage using CTAB method of DNA extraction as described by Doyle and Doyle (1990) with some minor modifications including phenol treatment and the final DNA concentration were adjusted to 60 ng for PCR analysis.

\section{Bulk Segregant Analysis (BSA)}

For bulked segregant analysis (BSA) (Michelmore et al., 1991), equal amounts of DNA were taken from 10 fertile plants and 10 sterile plants randomly from $F_{2}$ progeny and were pooled to create ' $F$ bulk' (BF) and 'S bulk' (BS), respectively. Initially the two bulk samples were subjected to analysis using SCAR marker to confirm polymorphism between parents and bulk samples to avoid the laborious screening of whole mapping population. Later, it was used for further screening of whole mapping population to identify the linkage with sterility.

PCR amplification was achieved in a Eppendorf Thermocycler (Eppendorf mastercycler Germany) programmed for initial denaturation at $94^{\circ} \mathrm{C}$ for 2 minutes, followed by 35 cycles; each cycle consisting of denaturation at $94^{\circ} \mathrm{C}$ for 45 seconds, primer annealing at $60^{\circ} \mathrm{C}$ for 45 seconds and primer extension at $72^{\circ} \mathrm{C}$ for 45 seconds and a final extension for 10 minutes at $72^{\circ} \mathrm{C}$ and hold at $12^{\circ} \mathrm{C}$. The PCR reaction was carried out in a final volume of $20 \mu$ l reaction mixture containing $60 \eta \mathrm{g}$ of template DNA, $0.2 \mathrm{X}$ buffer, $0.2 \mathrm{mM}$ dNTPs, $0.5 \mathrm{mM}$ of $\mathrm{MgCl}_{2}, 0.3$ $\mathrm{U}$ of Taq DNA polymerase, $0.025 \mathrm{pM}$ each of forward and reverse primer.

\section{Genotyping of $F_{2}$ population}

An $F_{2}$ segregation population size of 226 individual plants were screened using the SCAR 4 primer which showed polymorphism between BF and BS and SCAR profiles were generated using PCR and visualized on $2 \%$ Agarose gel and analyzed for further analysis.

\section{Analysis of SCAR profiles}

Amplification profiles obtained by SCAR 4 primer for parents and all $\mathrm{F}_{2}$ plants were estimated by comparing DNA fragment sizes on agarose gel with 100 bp DNA size markers. The bands were scored as ' $\mathrm{A}$ ' for the presence of band size same as female parent/seed parent i.e., sterile parent, scored as ' $\mathrm{B}$ ' for the presence of band size same as male 
parent/pollen parent i.e., fertile parent and scored as ' $\mathrm{H}$ ' for the presence of both the male sterile and fertile parent bands in case of heterozygous $\mathrm{F}_{2}$ plants.

\section{Results and Discussion}

Screening of SCAR 4 marker linked to the sterility gene

Initially the marker was screened for polymorphism between the parents used in the present study like male sterile line (IIHR10521AB) and a pure line (IIHRMY7). The analysis profile generated by SCAR 4 marker revealed a clear polymorphism between parents with same band size as reported previously. The primer produced amplification product size of 520 bp in sterile parent and $330 \mathrm{bp}$ size in fertile parent.

\section{Bulk Segregant Analysis}

Later, for bulked segregant analysis, the primer was used to screen for polymorphism between the Sterile bulk (SB) and Fertile bulk (FB) populations including parents again. The amplification profiles revealed a clear polymorphism between bulk populations with same amplicon size as in parent. To verify the implied linkage of this marker with male sterility locus, twenty individuals from the ' $F$ ' and ' $\mathrm{S}$ ' bulks were examined individually in more detail with respect to the polymorphic bands. The results of BSA with similar band pattern as in parents and bulks revealed that it may be linked to sterility (Plate 2). Subsequently, all the $226 \mathrm{~F}_{2}$ progeny were screened with the SCAR 4 marker to assess the primary linkage to the sterility locus.

\section{Screening of $\mathrm{F}_{2}$}

The segregating $F_{2}$ population of 226 plants, derived from a cross between Male sterile (IIHR10521AB) and inbred line (IIHRMY 7), comprised 164 male fertile and 62 male sterile plants (determined by flower morphology). Thus, the population displayed a 3: 1 ratio of male fertile (mf) to male sterile (ms) plants. This was consistent with the segregation of a recessive gene in the $\mathrm{F}_{2}$ population, and which was designated as Tems, a recessive gene controlling the male sterility in marigold.

Based on the analysis of profiles obtained by genotyping of $\mathrm{F}_{2}$ population obtained using SCAR 4 marker, it was clearly showed that the marker segregated very clearly and consistently fitting the mendalian ratio of 3:1 ratio except for few samples showing recombination when screened among $226 \mathrm{~F}_{2}$ populations showing that the marker is linked to male sterility in marigold (Plate 3 ). The primer SCAR 4 produced a band size of 520 bp in Sterile parent and 330 bp in Fertile parent and similar banding pattern was observed in sterile plants and fertile plants of $\mathrm{F}_{2}$ progeny and both the bands were present in case of heterozygous progeny (hybrids). The strong correlation of these polymorphic bands with the male sterility/fertility trait established that this SCAR 4 is linked very closely to the sterility gene and hence can be efficiently used for selection of parents in marker assisted breeding selection programmes.

\section{Screening and validation of SCAR 4 among different apetalloid sterile lines}

To further validate and confirm the linkage of SCAR 4 marker which was found to be linked to sterility gene locus via linkage map construction in the previous study, SCAR 4 was further screened among 12 different apetalloid male sterile lines (Table 1). The results of amplification profiles confidently revealed the linkage of SCAR 4 with the sterility gene locus in marigold by showing the similar banding pattern and polymorphism like in parents among different apetalloid sterile lines used (Plate 4). 
In any plant breeding and crop improvement programme of any crop species, the existence of male sterility play a vital role, since male sterility has been applied as an effective and economical means of pollination control in breeding programmes. Fortunately, the existence of male sterility in Marigold has blessed this ornamentally important crop in the development of commercially important hybrids. Male sterility mediated $\mathrm{F}_{1}$ hybrids are gaining more vogue and becoming profit oriented in many ornamental crops and also in Marigold. Identifying a molecular marker tightly linked to male sterility would permit the prior and planned manner of differentiating the sterile and fertile plants thereby concluding the breeding programme in a short time and in a very cost effective manner. After identification validating the linked marker is very much essential to assess the practical utility of linked marker as a step towards marker assisted breeding selection programme. Hence in the present, we have validated the previously reported SCAR marker linked to genetic male sterility in marigold for confirming its efficient utilization in MAS programme.

\section{Bulk Segregant Analysis (BSA)}

Based on the results of screening for polymorphism, SCAR 4 marker generated polymorphism between sterile and fertile parents and was selected for further screening of $\mathrm{F}_{2}$ mapping population. To avoid the laborious screening of a large number of $F_{2}$ plants for identifying the polymorphism of marker, we initially used Bulk segregant analysis strategy (Michelmore et al., 1991) to identify the linkage of marker by screening SCAR 4 marker among SP (Sterile Parent), FP (Fertile Parent), SB (Sterile Bulk) and FB (Fertile Bulk). Based on the results, the marker produced polymorphic bands between parents, SB and FB by showing clear polymorphic band size. Similarly, the BSA has been widely used in various crops by Hui et al., (2019); Thakur et al., (2014); Ragina and Sadhankumar (2013); Yanping et al., (2013); He et al., (2009) and Bi-Hao et al., (2009) for detecting markers linked to genes conferring particular character and is a powerful method for identifying molecular markers that show association with gene of interest or a specific region of the genome (Ren et al., 2012, Salinas et al., 2013).

\section{Screening $F_{2}$ population and apetalloid sterile lines}

To identify the markers linked to the Tems gene, SCAR 4 marker which showed polymorphism between two bulks, FB and SB in Bulk Segregant Analysis was screened among whole $226 \mathrm{~F}_{2}$ populations for further analysis of genetic distances and to reveal the preliminary linkage of marker to sterility. The results of genotyping revealed that the marker segregated consistently in 3:1 ratios for fertility and sterility with respect to the amplification of specific amplicons, except for few samples showing recombination or segregation distortion when screened among $226 \mathrm{~F}_{2}$ populations showing that it is tightly linked to male sterility in marigold. The segregation distortion is widespread in plant populations and is a common feature of plant genetic linkage maps. Both biological factors and technical problems potentially contribute to segregation distortion (Yanping et al., 2013). Also the results of screening of linked marker among twelve different apetalloid sterile lines revealed and confirmed the potential application of SCAR 4 marker in MAS breeding programmes for accurate selection of different lines by producing the same banding pattern as parents among different apetalloid sterile lines. This again validated the tight linkage of SCAR 4 marker with sterility gene locus in marigold thereby offering a powerful tool for accurate selection of parental lines at their early seedling stages itself through marker assisted selection (MAS). 
Table.1 List of apetalloid male sterile lines used for validation of linked markers

\begin{tabular}{|l|l|l|}
\hline SI. No & Apetalloid lines & Validation \\
\hline $\mathbf{1}$ & IIHRMOS-1 & Validated \\
\hline $\mathbf{2}$ & IIHRMOS-14 & Validated \\
\hline $\mathbf{3}$ & IIHRMOS-15 & Validated \\
\hline $\mathbf{4}$ & IIHRMOS-17 & Validated \\
\hline $\mathbf{5}$ & IIHRMOS-19 & Validated \\
\hline $\mathbf{6}$ & IIHRMOS-11 & Validated \\
\hline $\mathbf{7}$ & IIHRMOS-23 & Validated \\
\hline $\mathbf{8}$ & IIHRMOS-24 & Validated \\
\hline $\mathbf{9}$ & IIHRMOS-66 & Validated \\
\hline $\mathbf{1 0}$ & IIHRMOS-73 & Validated \\
\hline $\mathbf{1 1}$ & IIHRMOS-31 & Validated \\
\hline $\mathbf{1 2}$ & IIHR10521AB & Validated \\
\hline
\end{tabular}

Plate.1 Parents used for development F2 Mapping population

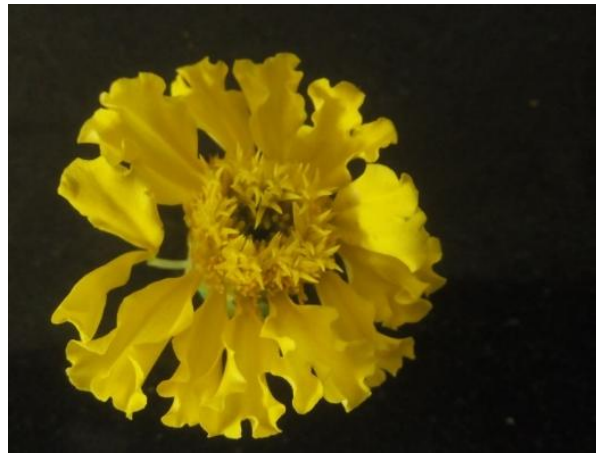

Mate Parent (Inbred line IIHRMY7)

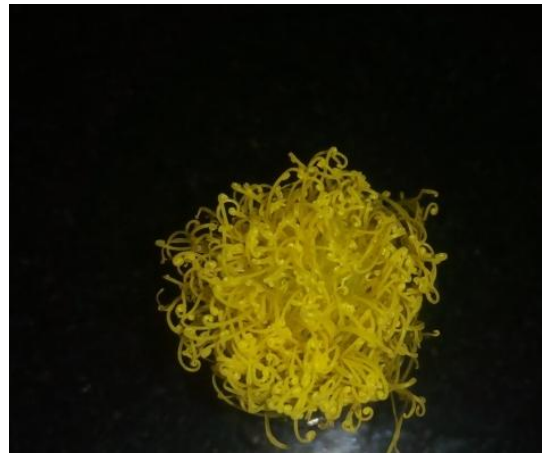

Female Parent (Apetalloid Sterile line IIHR10521AB)

Plate. 2 The PCR amplification of SCAR 4 marker in parents, Sterile Bulk (SB), Fertile Bulk (FB), Individuals of sterile and fertile bulks
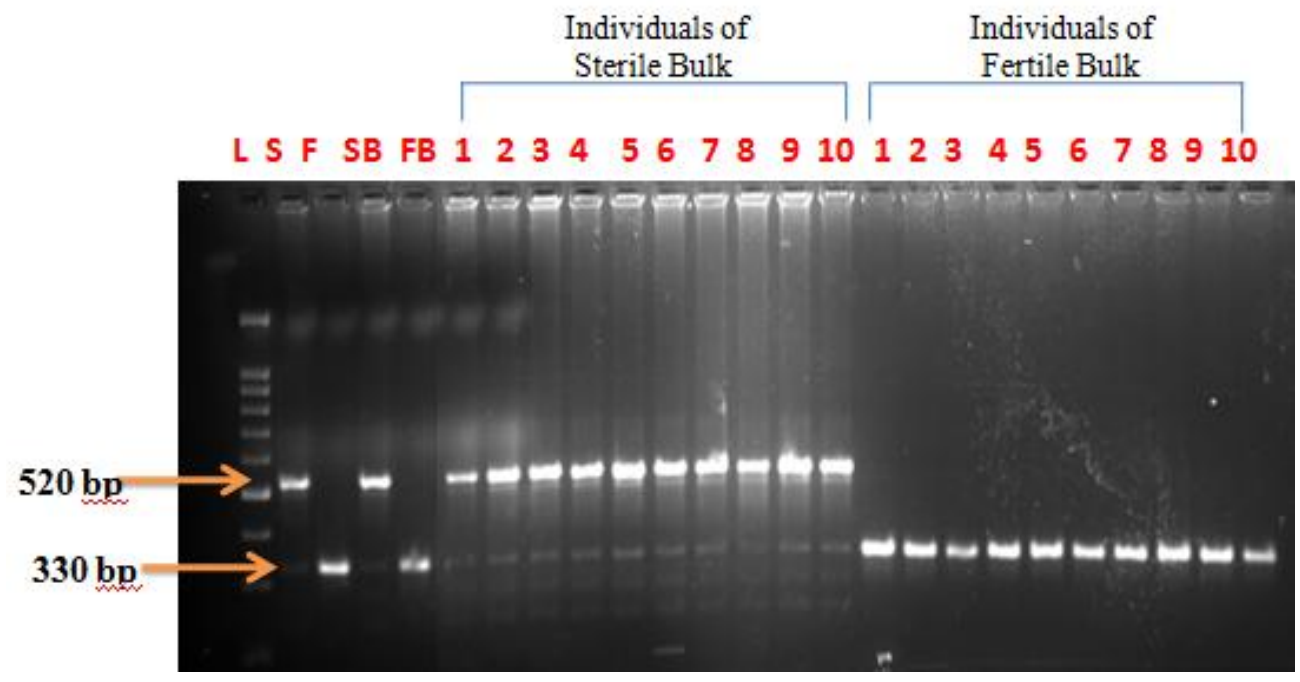
Plate.3 Genotyping of Parents and F2 progeny using SCAR 4 primer
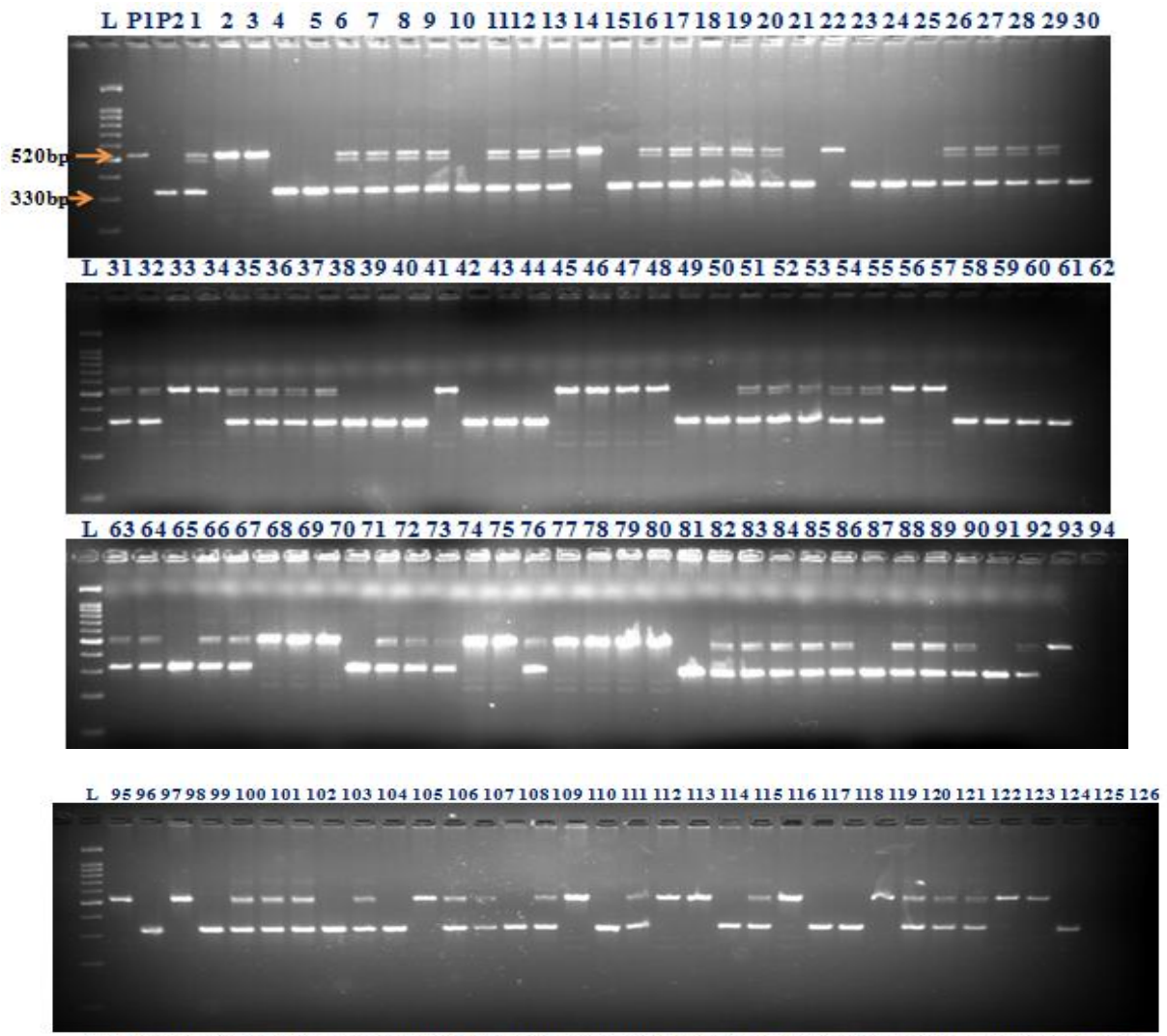

L 127128129130131132133134135136137138139140141142143144145146147148149150151152153154155156157158159160

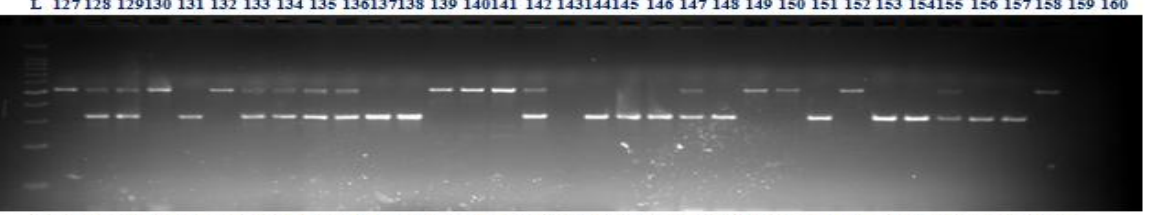

L 161162163164165166167168169170171172173174175176177178179180181182183184185186187188189190191192
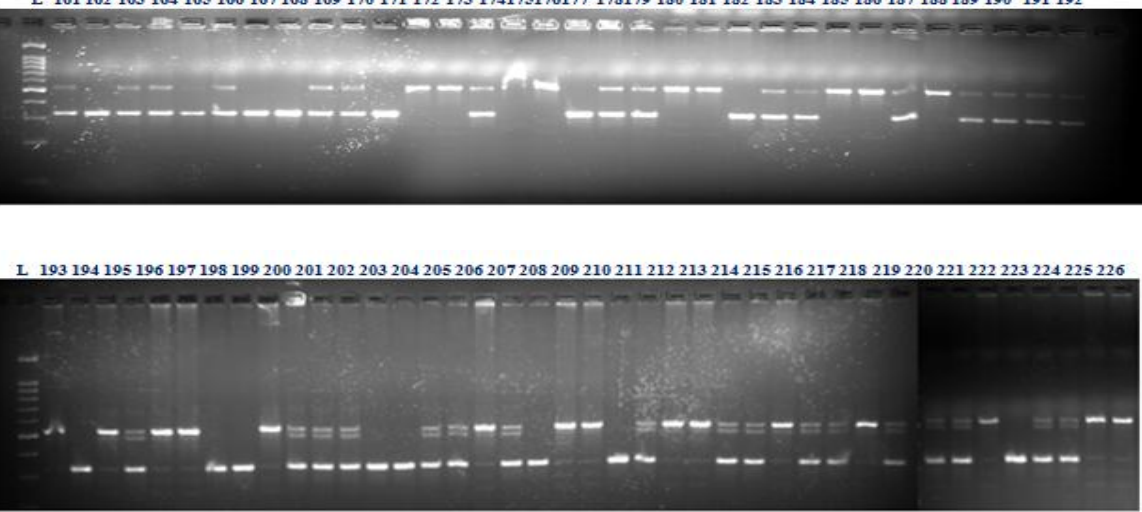

L- 1000 bp Ladder; P1- Sterile parent; P2- Fertile parent; 1-226 indicates the progeny of $\mathrm{F}_{2}$ 
Plate.4 Validation of sterility linked marker SCAR 4 in 12 different Apetalloid male sterile lines

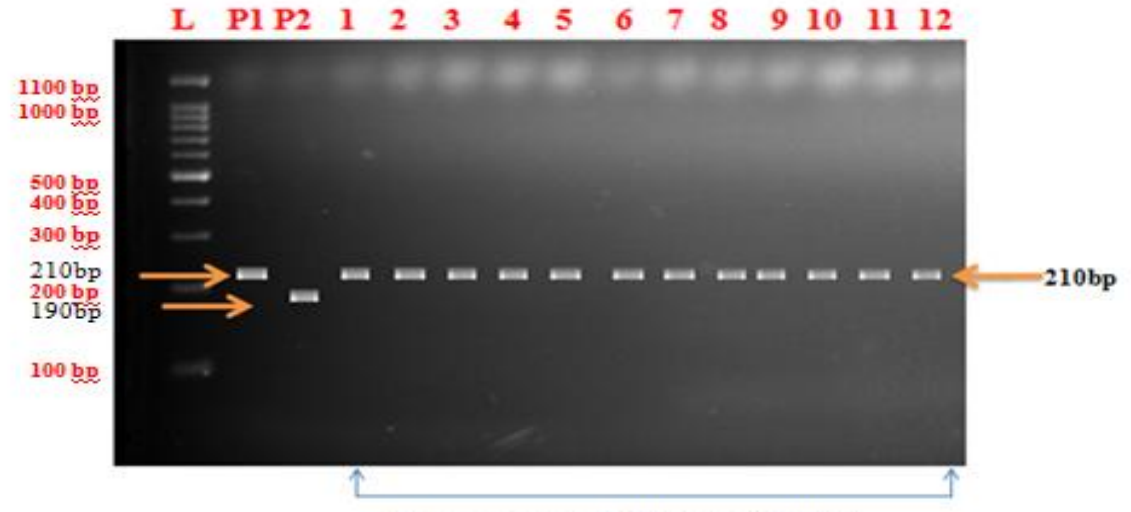

Different Apetalloid sterile lines

The results showed that how best this linked marker could be used as a selection marker in MAS breeding that facilitate narrowing down the population with fertile lines, retaining only sterile progenies during hybridization programme in marigold while developing outstanding hybrids. Similarly the markers identified to be linked to various traits in different crops have been validated for their use in MAS by Yagi et al., (2014) in Carnation (SSR marker linked to double flower type); Bhati et al., (2018) validated SSRs markers linked to $R f$ genes in diverse rice breeding lines. SCAR marker, SCU176534 linked to bacterial wilt resistant in tomato was validated for MAS by Kumar et al., (2018). SSR marker AVRDC-PP12 linked to the male sterility gene ms 10 in chilli was validated by Aulakh et al., (2017). SSR markers-linked to $R f$ locus in Rice were validated using eight tester lines by Raghavendra and Hittalmani (2015). Dhanya et al., (2014) validated the marker orf 725 linked to onion male sterility by screening different onion male sterile, maintainer and $F_{1}$ hybrids which resulted in the confirmation of identified molecular marker orf 725 is capable of distinguishing male sterile and maintainer genotypes. SCAR marker syau-scr04 linked to male sterility gene in Chinese cabbage, was applied for MAS by Hui et al., (2011) based on which the new male sterile line GMS4 with $100 \%$ male sterility and $100 \%$ male sterile plants was bred successfully and the linked SCAR marker syau-scr04 accurately determined the plant genotypes showing that it could be efficiently applied for markerassisted selection of the genetic male sterile line in Brassica spp. The two markers linked to sterility in welsh onion were confirmed by Gai et al., (2010) using seven welsh onion cultivars which accelerated the selection of sterile and maintainer lines in welsh onion breeding via MAS. The SSR (GBM1267) marker linked to male sterility in Barley was validated by Emebiri (2010). The SCAR marker (syau_scr01) and SSR marker (syau_m13) linked to male sterility in Chinese cabbage were verified using BC4 and BC5 populations which proved their application in marker assisted selection breeding (Hui et al., 2010).

In conclusion, once molecular markers have been linked to a trait of interest, these markers can be used to select desired lines from a large-scale population through markerassisted selection (MAS), which saves both costs and time. Hence, the validation of previously identified linked marker (SCAR 4 linked to sterility gene) in different genetic background of $\mathrm{F}_{2}$ and among different 
apetalloid male sterile lines in our study proved the potential application of identified linked marker (SCAR 4) which ultimately contribute for marker assisted selection breeding programme in marigold. MAS enable accurate selection regardless of environmental factors and it had been applied in breeding of various crops (Debener 2001), but to the best of our survey, the development of a commercial marigold cultivar through MAS has not been reported. Therefore, the demonstration on the validation of linked marker in the present study represents the use of SCAR 4 in MAS which showed an important advance in the breeding of marigold. These results serve as a valuable resource for genetic research in Marigold mainly in MAS.

\section{Acknowledgement}

This work was carried out at ICAR-IIHR, Hessaraghatta, Bengaluru where they have provided the planting material and lab facilities for molecular validation. We are greatly thankful and acknowledge the institute for allowing us to carry out the work and also for providing the facilities required for the work.

\section{References}

Ai, Y, Zhang Q, Pan C, Zhang H, Ma S, He Y and Bao, M., 2015, A study of heterosis, combining ability and heritability between two male sterile lines and ten inbred lines of Tagetes patula. Euphytica. 203: 349-366.

Aulakh, P. S., Dhaliwal, M. S. and Jindal, S. K., 2017, Validation of molecular marker AVRDC-PP12 linked to male sterility gene $m s 10$ of chilli. Indian Journal Horticulture. 74(4): 126-135

Bhati, P. K., Singh, S. K. and Kumar, U., 2018, Screening and validation of Fertility Restoration Genes $(R f)$ in Wild
Abortive CMS system Rice (Oryza sativa L.) using microsatellite markers. Indian Journal of Genetics and Plant Breeding. 78(2): 270-274.

Bi-Hao, C., Jian-Jun, L., Yong, W. And Guoju, C., 2009, Inheritance and identification of SCAR marker linked to bacterial wilt-resistant in eggplant. African Journal of Biotechnology. 8(20): 5201-5207.

Chen, C., Zhuang, M., Fang, Z. Y., Wang, Q. B., Zhang, Y. Y., Liu, Y. M., Yang, L. M. and Cheng, F., 2013, A coDominant marker BoE332 applied to Marker-assisted selection of Homozygous Male-Sterile Plants in Cabbage (Brassica oleracea var. capitata L.). Journal of Integrative Agriculture. 12(4): 596-602

Darwin, C., 1877, The different forms of flowers on plants of the same species. Murray, London.

Debener, T., 2001, Molecular tools for modern ornamental plant breeding and selection. Acta Horticulturae. 552: 121127

Deineka, V. I., Sorokopudov, V. N., Deineka, L. A. and Tretyakov, M. Y., 2008, Flowers of marigold (Tagetes) species as a source of xanthophylls. Indian Journal of Horticulture Research. 68: 126-134

Dhanya, V. S., Shetty, H. V., Gowda, R. V. and Reddy, D. C. L., 2014, Screening of Molecular markers linked to male sterility in Onion (Allium cepa L.) genotypes and its validation. Plant Archives. 14(1): 301-305

Doyle, J.J. and Doyle, J.L., 1990, Isolation of plant DNA from fresh tissue. Focus. 12: 13-15.

Emebiri, L. C., 2010, An EST-SSR marker tightly linked to the Barley male sterility Gene (msg6) located on chromosome 6H. Journal of Heredity. 101: 769-774 
Gai, S. P. and Meng, X. D., 2010, Application of Molecular Markers linking to cytoplasmic male sterile loci to Assist Maintainer Line Selection and their Selection Efficiency in Welsh Onion (Allium fistulosum L.). Journal of Integrative Agriculture. 9(11): 15711576

He, Y.H., Ning, G.G., Sun, Y.L., Qi, Y.C. and Bao, M.Z., 2009, Identification of a SCAR marker linked to a recessive male sterile gene (Tems) and its application in breeding of marigold (Tagetes erecta). Plant Breeding. 128(1):92-96.

He, Y.H., Ning, G.G., Sun, Y.L., Hu, Y., Zhao, X.Y. and Bao, M. Z., 2010, Cytological and mapping analysis of a novel male sterile type resulting from spontaneous floral organ homeotic conversion in marigold (Tagetes erecta L.). Molecular Breeding. 26(1):19-29.

Hui, F., Lili, W., Peng, W., Zhiyong, L., Chengyu, L., Yugang, W., Ruigin, J., Huanging, Z., 2010, Verification of the utility of molecular markers linked to the multiple- allele male sterile gene Ms in the breeding of Male- sterile lines of Chinese cabbage (Brassica rapa). African Journal of Biotechnology. 9(35): 5623-5628

Hui, F., Ning, Y., Zhiyong, L. and Hao, W., 2011, A genetic Male Sterile Line Developed by Molecular markerassisted selection in Chinese cabbage (Brassica rapa ssp. pekinensis). African Journal of Biotechnology. 10(77): 17706-17711

Hui, L., Defang, L. and Linig, Z., 2019, Identification and validation of single nucleotide polymorphism markers linked to first flower node in Kenaf by using combined specific-locus amplified fragment sequencing and bulked segregant analysis. Industrial crops and products, 128: 566-571
Kumar, S., Gowda, P. H. R., Saikia, B., Debbarma, J. and Velmurugan, N., 2018, Screening of tomato genotypes against bacterial wilt (Ralstonia solanacearum) and validation of resistance linked DNA markers. Australasian Plant Pathology, 47: 365374

Li, Y., Liu, Z., Cai, Q., Yang, G., He, Q. and Liu, P., 2011, Identification of a microsatellite marker linked to the fertility-restoring gene for a polima cytoplasmic male-sterile line in Brassica napus L. African Journal of Biotechnology. 10(47): 18205-18212

Michelmore, R. W., Paran, I. and Kesseli, R. V., 1991, Identification of markers linked to disease-resistance genes by bulked segregant analysis: a rapid method to detect markers in specific genomic regions by using segregating population. Proceedings of National Academy Sciences. 88: 9828-9832

Padalia, H., Moteriya, P. and Chanda, S., 2014, Green synthesis of silver nanoparticles from marigold flower and its synergistic antimicrobial potential. Journal of the Science of Food and Agriculture. 72(3): 283-290.

Raghavendra, P. and Hittalmani, S., 2015, Identification of Maintainer Lines and Validation of SSR markers for development of New Rice Hybrids for Aerobic Situation. An International Journal of Rice. 52(3): 173-180

Ragina, V. C. And Sadhankumar, P. G., 2013, Molecular marker analysis for bacterial wilt resistance in mapping populations of tomato. Vegetable Science. 40 (2): $155-158$.

Ren, Y., Li, Z., He, Z., Wu, L., Bai, B., Lan, C., Wang, C., Zhou, G., Zhu, H. and Xia, X., 2012, QTL mapping of adultplant resistances to stripe rust and leaf rust in Chinese wheat cultivar Bainong 64. Theoretical and Applied Genetics. 
125: 1253-1262.

Salinas, M., Capel, C., Alba, J. M., Mora, B., Caurtero, J., Fernandez-Munoz, R., Loza-no, R. and Capel, J., 2013, Genetic mapping of two QTL from the wild tomato Solanum pimpinellifolium L. controlling resistance against twospotted spider mite (Tetranychus urticae Koch). Theoretical and Applied Genetics. 126: 83-92.

Singh, V., Panwar, G. S. and Singh, J., 2013, Validation of SSR markers for fertility restorer gene in Drought Tolerant Advanced Breeding Lines of Rice (Oryza sativa L.). Crop Research. 45(13): 66-73

Sowbhagya, H.B., Sampathu, S. R. and Krishnamurthy, N., 2004, Natural colourant from marigold-chemistry and technology. Food Reviews International, 20 (1): 33-50.

Tanksley, S. D., N. D. Young, A. H. Paterson, and M. W. Bonierbale, 1989: RFLP mapping in plant breeding: new tools for an old science. Biotechnology. 7: 257-264.

Thakur, P. P., Mathew, D., Nazeem, P. A., Abida, P. S., Indira, P., Girija, D., Shylaja, M. R. and Valsala, P. A., 2014, Identification of allele specific AFLP markers linked with bacterial wilt [Ralstonia solanacearum (Smith) Yabuuchi et al.,] resistance in hot peppers (Capsicum annum L.). Physiological and Molecular Plant pathology. 87: 19-24.

Verghese, J., 1996, Focus on xanthophylls from Tagetes erecta $\mathrm{L}$ the giant natural complex-1. Indian Spices. 33(4): 8-13.

Verghese, J., 1998, Focus on xanthophylls from Tagetes erecta $\mathrm{L}$ the giant natural color complex- II. Indian Spices. 34(1\&2): 13-16.

Yagi, M., Yamamoto, T., Isobe, S., Tabata, S., Hirakawa, H., Yamaguchi, H., Tanase, K. and Onozaki, T., 2014, Identification of tightly linked SSR markers for flower type in carnation (Dianthus caryophyllus L.). Theoretical and Applied Genetics. 312: 542-551

Yang, R. M., Yuan, N. X., Hao, W., Fei, C., Hua, T. J., Xiang, H. J., Rong, L. D. and Yi, Z. J., 2012, Inheritance of Sterility of Genic male sterile line (20118A) and Marker-assisted selection in Hybrid breeding of Brassica napus L. Acta Agronomica Sinica. 38(11): 2015-2023

Yanping, Z., Hui, L., Hairui, Z. And Gao, G. 2013, Identification and Utility of SRAP markers Linked to Bacterial wilt resistance gene in Potato. Vegetos. 26: 131-138.

Zhang, J. C., J. R. Xu, F. R. Li, and Y. L. Shen, 2005: Review of studies on African marigold (Tagetes erecta L.). Southwest Horticulture. 33: 17-21.

\section{How to cite this article:}

Asha, K.M., Anuradha Sane, Tejaswini, D.C. Lakshaman Reddy, Sateesha R. Patil, Sarvamangala S. Cholin, Mahantesha B.N. Naika and Raghavendra Gunnaiah. 2019. Validation of SCAR Marker Linked to Genic Male Sterility in Marigold: As a Forward Step towards Marker Assisted Breeding Programme. Int.J.Curr.Microbiol.App.Sci. 8(02): 33733383. doi: https://doi.org/10.20546/ijcmas.2019.802.393 